\title{
The Impact of Globalization with Privatization on Employees Benefit: A Case Study of Pakistan
}

\author{
Farrukh Zafar \\ Lecturer Department of Business Administration \\ Nazeer Hussain University \\ Karachi - Pakistan \\ farrukh.zafar@nhu.edu.pk \\ $\&$ \\ M. Faseeh Ullah Khan \\ Assistant Professor \\ Department of Business Administration \\ Nazeer Hussain University \\ Karachi - Pakistan \\ m.faseeh@nhu.edu.pk \\ $\&$ \\ Saif-Ur-Rehman \\ Lecturer Department of Business Administration \\ Nazeer Hussain University \\ Karachi - Pakistan \\ saifur.rehman@nhu.edu.pk
}

\begin{abstract}
The objective of this research is to enquire about all the major aspects of privatization. It is evident from the government policy that we observe now days that organizations which were previously owned by government are now privatize but what are the impacts that are created on employees. Therefore, we have discussed with different aspects of employees like compensation, harassment, job security \& social security. These factors are also studied in depth under literature review. This research belong to Pakistan only and studied different people from different backgrounds. A questionnaire of sample size 180 respondent.
\end{abstract}


Keywords: Employee compensation, Employee harassment, Job security, Privatization, Social Security.

\section{INTRODUCTION}

\subsection{Overview:}

Making organization effective and efficient is most essential in any national economic growth. In various diverse approaches to accomplish this goal however the tactics that the government can use to fulfill its objectives is to privatize is national assets. This would lead to appropriate allocation of its assets and is for the most part considered to build execution of state possessed or open segment firms. Privatization offer benefits of open area firms to the overall population.

The world came to familiar with the term Privatization in 1970s. However soon it spread all around the globe. Privatization turned out to be exceptionally normal and legal in light of the fact that it has incredible effect on execution and productivity of firms. In light of this thought. Privatization is turning out to be more vital to change the structure of firms of creating nations.

\subsection{Problem Statement:}

Our focus in this research is to find out is employee welfare better serve under privatized firms or not? For the past few years we are looking at different organization getting privatize but what is the impact it created at employees? Are they really insecure? This research wills lead us to the employee's insight.

\subsection{Objectives of the study:}

The objective of this study is to determine whether privatization has impacted positively on employee's social security, job security \& employee's compensation etc. This is very crucial and one of the most important factors that need to be considered while makes a privatization decision as employees are also the stake holders of any organization.

\subsection{Significance of the study}

In today's world privatization has become a great challenge by all the nations around the globe. This study will be helpful to analyze the impact of privatization on 


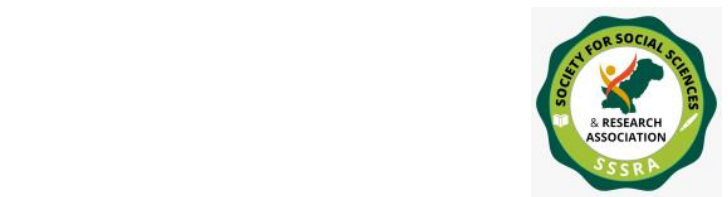

Pak. Journal of Int'L Affairs, Vol 3, Issue 2 (2020) The Impact of Globalization with Privatization...

employees. This study will be helpful for management and employees to compare the psychological effects before and after privatization regarding their welfare and needs. The government are far more concern with economic benefits and performances of organizations that comes under government management. This study revolves around the comparison before and after privatization. This study is different from the previous studies as there has never been such research in this area. The current study aims to address regarding the effects of privatization on employees and their welfare.

This study will be very helpful to realize what are the most concerns of employees and remove the concerns of employees that are being faced and affect the performance.

\section{Literature Review}

According to Birdsall and Nellis (2003), he says that privatization brings the negative change it is a perception developed that privatization brings injustice in the form of downsizing, effects less privilege class along with middle class. As it has witnessed that people from white color jobs gets fired in no time. Some this also leads to higher inflation. These people who are supposed to be national asset are now being waste not only this but corruptions also take part in privatization and the objective of privatization can be achieved as it could. This will only benefit to upper class and corrupt government officials only.

Prizzia (2013), in a research article enlighten the adverse effects of privatization along with the proofs that were required to prove his work for example, he highlights certain nations that have adopted privatization policy like privatization process of irrigation in Bolivia and power in Thailand that created unemployment at large number and the concept of welfare was nearly eradicated has ended up in huge inflation and large number of protest started in both of these nations.

Similarly, Cato (2008) reveled in his research that the nations that have balanced firms national and private are much more efficient and effective as compared to others. They are much more welfare oriented and the employees are much more satisfied with them. As these organizations are well regulated by government and welfare became its responsibility. Impacts on employees are loss of occupations, changes in workplace, and stress because of unreliability of employment, pay cuts and so forth. Wagle (1995) is of the perspective that in as opposed to mainstream thinking, specialists regularly 


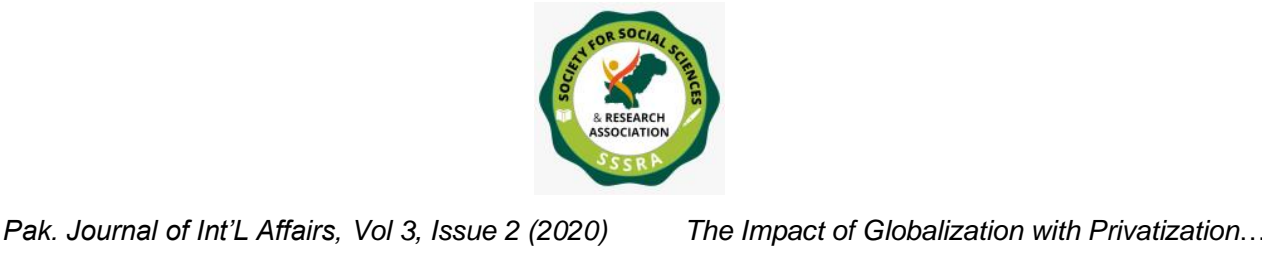

have picked up from privatization as new ventures and element development have brought about new job.

Kikeri (1998) it has been observed that most of the time employees are hired at lower salary as compared to government organization, this created a hidden unemployment. As it is a trend set by all the nearby employers. This tends to higher staffing until the project is done and suddenly after the accomplishment they are terminated. This phenomenon leads the rush towards government employment.

According to Gabel (1987) the privatization has two possible aspects first: is a money related matters that funds inflows to government. The second is the exchange of the power to settle on asset distribution choice.

Moyo and Kinuthia (1998) empowering situation with the expectation of work as a technique for practical financial improvement. Earlier studies agree with the view that privatizations bring the harmony and wealth to the nations as this leads to great efficiency. Support that if there is changes in proprietorship then it will bring about more prominent proficiency.

Eckel, Eckel and Singal (1997) As if there should be an occurrence of British Airways proprietorship change brought about higher effectiveness and because of progress in possession stock costs of their rivals compare with British Airways.

Salih (2000) suggested that an employee would be beneficial if he deliver value more than the cost of his employment. He further says that higher number of employees hired by the government enterprises only because of political pressure. He also placed an example of Sri Lankan state that were force to have more employees just decrease the unemployment. This would definitely decrease unemployment rate but the organizational efficiency is lost somewhere and ultimate objective if firms at micro level won't be achieved.

Birdsall and Nellis (2002) suggested that privatization brings the negative change in economy as it decreases the employment at higher rate whereas much lesser new jobs are created. New employees are force to overwork and under great pressure.

Most unpleasant and most horrible aspect of privatization is a fear of getting 


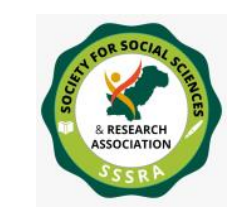

Pak. Journal of Int'L Affairs, Vol 3, Issue 2 (2020) The Impact of Globalization with Privatization...

unemployed. Employees are treated as a tool and options. As indicated by Aghaei, Hasanzadeh, Mahdad and Atashpuo (2010), employees are really becoming worried and as it has been witness whenever and wherever the privatization takes place, jobs are cut down and large number of employees are lay off. This creates a great doubt in the mind of employees. This creates a huge stressful life even though after privatization employees are on job yet a fear of job loss remains there.

Birdsall and Nellis (2003) discernment that privatization is on a very basic level uncalled for in both idea and execution: it is seen as hurting poor people, the disappointed, the specialists, and even the working class; tossing individuals out of steady employments into poor ones or unemployment. It is clear that open ventures were overfilled, regularly seriously so; that in planning for privatization, open undertaking business numbers declined. Generally speaking, the proof shows that a bigger number of individuals have lost employments than picked up them through privatization.

Birdsall and Nellis (2002), while showing their examining of the confirmation, communicated that a bigger number of individuals have lost employments than picked up them through privatization. Pieters (2006) remarked augmenting that now the vital inquiry of what sort of employments individuals find after release from open accomplishments is simply starting to get consideration.

As per CEC (2007), the fear of occupation misfortunes is the difficulty to privatization. Where the administration's energy base is in urban focuses, exchange unions make livelihood the most obvious issue in the privatization bargain. Politically the most troublesome and feared effect of privatization is representative cutbacks. The fear is supported in light of the fact that numerous open undertakings are significantly congested, as they are regularly utilized as instruments of occupation creation.

As indicated by Martin (2009) privatization ordinarily is connected with diminishment and rearrangement of the work power, either in planning for privatization or soon a short time later. Einarsen, Raknes and Matthiesen (1994) uncovered that an allinclusive worry in privatization procedure is the impact it has on work. Numerous spectators expect that privatization will bring about significant employment misfortunes. 


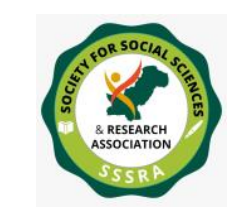

Pak. Journal of Int'L Affairs, Vol 3, Issue 2 (2020) The Impact of Globalization with Privatization...

As per Nalingigwa (2008), notwithstanding the worry about possible occupation misfortunes, considers attempted by World Bank demonstrated that "African government have done next to no to track the impacts of privatization on vocation." Not just that privatization is bringing on unemployment in Tanzania. In light of the fact that more than 70 ventures were shut and laborers lost their employments. Bhaskar and Khan (1995) inferred that in spite of every one of these successes the administration objective to job rate has not been met following a large portion of specialists loses their jobs which is the greatest negative impact of privatization.

This was further conformed by Pamacheche and Koma (2007) a genuine concern for workers, in spite of the fact that there are a couple of special cases to this. There are certain advantages of this process:

(i) New jobs are created after privatization;

(ii) Compensation packages had a tendency to enhance after privatization, and;

(iii) Numerous purchased offers at marked down costs in the privatized firms and these profited when offer costs in the end rose. Many of the employees lose their jobs as a consequence of privatization, such workers had a tendency to get large compensation packages. Compensation and retirement motivating forces purchase work boost and permit privatization. Now and again, the decline in the level of livelihood occurs preceding privatization and accordingly, could be credited to the requirement for more prominent proficiency, and not simply privatization. In situations where closed down ventures were re-opened by private financial specialists, workers profited specifically.

Kikeri (1998) struggled that numerous happenings have been privatized with their work power in place, either in light of the fact that expanding rivalry encouraged work power alterations under open possession or on the grounds that new private financial specialists were willing to tackle unassuming. Specialists obtaining so as to stay with privatized firms have frequently profited better-paying occupations, organization shares, and enhanced preparing and profession improvement prospects. Referring Hachette, Luders and Tagle (1993) that when all is said in done, privatization has slightly affected inclination in nations that did work changes well before privatization. Chile, for instance, started broad work market changes in parts, for example, information transfers and power brought about no cutbacks. Truth be told, business in these organizations expanded by 10 percent as an aftereffect of general enhancements 


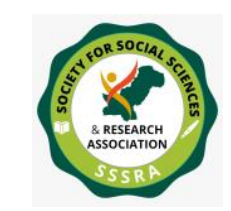

Pak. Journal of Int'L Affairs, Vol 3, Issue 2 (2020) The Impact of Globalization with Privatization...

in the economy additionally of the new speculations that went with privatization. Privatization has likewise minimally affected specialists in aggressive undertakings. Ghana, Mexico, Morocco, and Tunisia are among numerous nations that have possessed the capacity to offer such activities with their work drive pretty much in place. However extensive inclination decreases have frequently gone with the privatization of state undertakings that were, before, forcefully sponsored and shielded from rivalry.

In an examination about Tanzania Nalingigwa (2008) reported that pay rates and different incentives for specialists have been expanded and enhanced, for instance before privatization the most reduced pay in addition to different motivations. New proprietors might diminish compensation as a feature of a general cost-cutting approach, however in the event that the firm grows; it might bring to the table higher wages to draw in new specialists. New private proprietors might likewise will probably embrace expertise one-sided advancements, bringing about a compositional movement toward more generously compensated laborers. Conditional upon the relative quality of such elements, wages might either rise or fall as a consequence of privatization. The Upjohn Institute, as a team with accomplices from Heriot-Watt University in Edinburgh and the Central European University Labor Project in Budapest, has as of late attempted an exact examination of the impacts of privatization on the pay bill, job, and wage rates of firms in Hungary, Romania, Russia, and Ukraine-nations where a large number of organizations were privatized in a moderately brief timeframe amid the 1990s. These four nations had shifted accomplishment with privatization changes. Hungary was viewed as a standout amongst the best, Russia and Ukraine were less fruitful, and Romania was some place in the center. The new research in this venture, in any case, finds no confirmation of extensive detailed negative results of privatization for business and wages.

Sometimes these are treated as blessing as cheap labor is available, Hicks (1963) simultaneously men power can be raised specially those nations where it lacks and skilled labour can easily be available. On the other hand, this can be a disaster as many economic, financial and social issues may rise. According to Devadoss and Luckstead (2008) in 2002 US agriculture sector, worker's majority was migrant with almost 96\% of them were unauthorized. Whereas according to Zahniser, Hertz, Dixon and Rimmer (2012) says if there is a large cut-off in illegal immigrant than there would be decline in economic growth and economy would get slower in long run. 


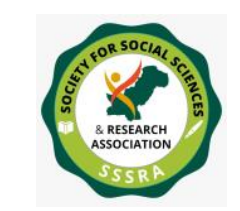

Pak. Journal of Int'L Affairs, Vol 3, Issue 2 (2020) The Impact of Globalization with Privatization...

As indicated by Pamacheche and Koma (2007) and Khan, Munawar, Yaqub, Faisal and Khan (2011), privatization is in light of a legitimate concern for workers and when the commercial ventures are given in the private hands their execution is expanded complex; compensation bundles had a tendency to enhance since employees are given better wages and pay rates with a specific end goal to enhance their efficiency and maintenance in the business. Martin (2009) communicated that privatization can be taken after instantly by more awful terms and conditions, yet such an underlying effect can be turned around later when a rebuilt organization can compensate workers for their commitment to its prosperity with upgrades in pay and conditions. Be that as it may, the opposite starting change took after by later disintegrating has additionally happened. Martin cited illustrations of decrease of pay rates because of privatization of numerous nations as specified in taking after lines. at most, stand out individual separated from the primary provider could be bolstered by the pay, contrasted with four individuals in 1985. Likewise, wellbeing and training sponsorships declined. In Poland, normal wages and pay rates fell by 27 for each penny somewhere around 1989 and 1992, opening up inequalities in pay. An investigation of ten privatized Polish organizations uncovered a propensity for wages to increment forcefully promptly after privatization however to quit doing as such soon a short time later for execution related pay motivators. In Estonia, outside proprietors have blocked boosts in compensation. A law on aggregate bartering, which produced results.

Martin (2009) communicated that it is the responsibility of world bank and IMF to enforce and guide a proper work and standard, as due to lower salaries employees are offering jobs to those who are not eligible for those or the people who deserve more were paid less. This leads to inefficiency as people are not doing according to the performance is required especially in the case of Soviet Union and they must work according to the Ullrich (2001). Once in a while for a considerable length of time at once, has likewise brought on awesome hardship on workers. Now and then, at times, administrators have purposely withheld compensation because of workers in the trust of fiscally constraining them to offer (to the supervisors) their privatization vouchers at knock down costs.

Megginson and Netter (2001) communicated that now and again, the genuine size of unemployment is questionable as due to political influence the more and more employees get hired irrespective of their efficiencies and capabilities which leads to skilled labor waste and underutilization of the maximum capacity. In the state owned 


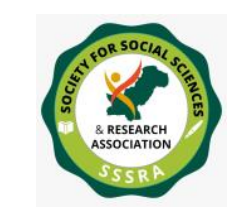

Pak. Journal of Int'L Affairs, Vol 3, Issue 2 (2020) The Impact of Globalization with Privatization...

organization employee's efficiency are much lesser as it could be. These jobless employees or employees having lower salary will have a major impact on their families and on the social life too. Some nations although having all time least unemployment still suffer and not up to the mark. This can only be justified by the act of lower salaries. In any case, the outside speculation that can have entered impact in determining those difficulties can likewise bring different issues. As privatization empowers in the past shut economies to join the globalization pattern, livelihood opportunities can dissolve, as the Tung ram case in Hungary illustrates.

\section{RESEARCH METHODOLOGY}

The research method is based on primary data means of collecting data. The data collection method for this study is based on qualitative analysis which is carried out by means of questionnaire. The data collection specified information comprises of closedended questions. The sample size for this study is selected to be 180 respondents as obtained by applying Probability sampling technique on the designed target population. The questionnaire consists of 16 questions that are both close ended. The information is collected through provided information as mentioned on the questionnaire. Likert scale is used ranging from ( $1=$ Strongly Disagree to $5=$ Strongly Agree). Numerically.

The reliability analysis of mentioned variables is conducted through Cronbarch's alpha. While, the validity test is performed to measure the suitability of criterion to be covered by means of reliability. This research is based evaluating the reliability construct of research instrument.

\section{RESULTS}

In our research we have taken a sample of 180 respondent collected through survey questionnaire for its analysis we have used Likert scale. In this chapter we will try to build a relationship between our variables by using Pearson correlation.

Firstly, we have measured reliability test to make sure that the respondent represents a true and reliable values. For this we have used Cronbach's alpha for analysis. This tool is frequently used to measure reliability. the Cronbach's alpha is 0.8 , which establishes the high level of consistency for the scale. 


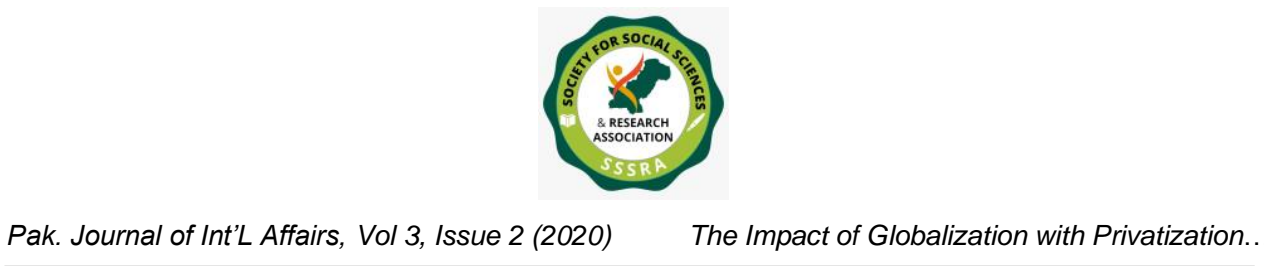

We use regression (R), coefficient of determination (R2) \& Adjusted R2. We use regression to determine the relationship magnitude as in this table we can see the relationship is strongly positive 0.964 or $96.4 \%$. Similarly, we use coefficient of determination for same reason and we also get its result strongly positive 0.929 or 92.9\%. Whereas we use Adjusted R2 that determine is there any irrelevant variable but here in this case we don't have.

The ANOVA table above demonstrates the overall regression model which shows good fit for the data. The table also identifies the independent variable that statistically significant to forecast the dependent variable, $\mathrm{P}<0.0005$. This shows goodness of fit in the data.

\section{CONCLUSION}

From this research we can understand the impacts of privatization on any organization. We have discovered that there is a major role played by compensation in private sector whereas other factors like Job security, harassment and social security does not play any effective role in privatization. From this point it is clear that people would prefer the government jobs much more if their compensation is increased. This confirmation that people would be satisfied \& motivation with government but the only factor that need to be dealt is strict policy \& regulation implementation. This would lead to be ideal situation and there would be no need to privatize any organization. 


\section{REFERENCE}

Aghaei, A., Hasanzadeh, R., Mahdad, A., \& Atashpuor, S. H. (2010).

Occupational stress and mental health of employees of a petrochemical company before and after privatization. International Journal Occupation Environmental Medicine (The IJOEM), 1(2 April).

Cato, S. (2008). Privatization and the Environment. Economics Bulletin, 12(19) $1-10$.

Kikeri, S. (1997). Privatization and Labor: What Happens to Workers when Governments Divest?. World Bank Technical Paper, 396, Washington DC: The World Bank.

Martin, B. (1997). Social and Employment Consequences of Privatization In Transition Economies: Evidence And Guidelines. ILO. http://www.ilo.int/wcmsp5/groups/public/---ed_emp/--emp_ent/documents/publication/wcms_126672.pdf.

Nalingigwa, P. A. (2013). Impact of Privatization on Public Enterprises Case of Tanzania.

Nancy and Nellis, J. (2003). Winners and Losers: Assessing the Distributional Impact of Privatization, World Development, Elsevier Ltd. 31(10), 16171633.

Pamacheche, F., \& Koma, B. (2007). Privatization In Sub-Saharan Africa-An Essential Route To Poverty Alleviation. African Integration Review, 1(2), $1-22$.

Prizzia, R. (2005). An International Perspective of Privatization and Women Workers. Journal of International Women's Studies. 7(1). http://www.bridgew.edu/soas/jiws/Nov05V1/Prizzia.pdf 
Salih, R. (2000). Privatization in Sri Lanka. Privatization in South Asia:

Minimizing Negative Social Effects through Restructuring. New Delhi: International Labour Organization.

Ullrich, G., Essenberg, H., Ratteree, W., Hoffmann, E., \& Hammouya, M. (2001).The Impact of Decentralization and Privatization on Municipal Services: Report for Discussion at the Joint Meeting on the Impact of Decentralization and Privatization on Municipal Services, Geneva, 2001. ILO. 